\title{
Historia natural de Macrotera pipiyolin (Hymenoptera: Andrenidae) en la Estación de Biología Chamela, Jalisco, México
}

\author{
Natural history of Macrotera pipiyolin (Hymenoptera: Andrenidae) in the Estación de Biología \\ Chamela, Jalisco, Mexico
}

\author{
Beatriz Rodríguez-Velez ${ }^{1 *}$ y Ricardo Ayala ${ }^{2}$ \\ 'Instituto de Biología, Departamento de Zoología, Universidad Nacional Autónoma de México. Apartado postal 70-153, 04510 México, D.F., México. \\ ${ }^{2}$ Estación de Biología Chamela, Instituto de Biología, Universidad Nacional Autónoma de México. Apartado postal 21, San Patricio, 48980 Jalisco, \\ México. \\ *Correspondencia: brodriguez@ibiologia.unam.mx
}

\begin{abstract}
Resumen. Se presenta información sobre la historia natural de Macrotera pipiyolin; el estudio se realizó en la Estación de Biología Chamela, Instituto de Biología, UNAM, entre junio y agosto de 1994. Las abejas emergieron poco después del inicio de la temporada de lluvias, su pico de actividad fue a principio de julio, presentando alrededor de 35 días activos. La actividad concuerda con la floración de Opuntia excelsa, planta de la que obtiene sus recursos. Las cópulas ocurren sobre las flores y los machos muestran 3 tipos de estrategias reproductivas: macho dominante, subordinado y patrullero. Las hembras son poliándricas y los machos polígamos. Las hembras construyen los nidos generalmente cerca de $O$. excelsa y tienen una distribución gregaria. Los nidos son simples, con un túnel principal y celdas, las que se cierran y desconectan del tunel una vez que se han aprovisionado y en ellas se ha depositado un huevo. Para la provisión de una celda se requiere de 2 a 18 cargas de polen. El desarrollo de huevo a larva adulta ocurre en 1 mes, posteriormente la larva permanece en este estado aproximadamente por 10 meses, y la pupa se presenta pocos días antes de la emergencia.
\end{abstract}

Palabras clave: reproducción, anidación, dimorfismo, poligamia, poliandria, oligoléctica.

\begin{abstract}
Information on the natural history of Macrotera pipiyolin in the Estación de Biología Chamela (IBUNAM), based on observations made between June and August 1994 is presented. Bees emerged shortly after the rainy season; their peak of activity was in early July, with 35 days of activity. The activity of the bee is consistent with the flowering of Opuntia excelsa, the plant that provides its resources. Mating occurs on flowers, where males present 3 types of reproductive strategies: dominant, subordinate, and patrolling. Females are polyandrous and males are polygamous. Females usually build nests near $O$. excelsa and they have a gregarious distribution. The nests are simple with a main tunnel; after cells are provisioned with pollen and an egg is oviposited, they are closed off from the main tunnel. To provide a cell requires from 2 to 18 loads of pollen. The development from egg to larva occurs in 1 month, after which the larvae remain in this state for 10 months and the pupae appear a few days before emergence.
\end{abstract}

Key words: reproduction, nesting, dimorphism, polygamy, polyandry, oligolecty.

\section{Introducción}

El género Macrotera Smith, 1853 (Andrenidae: Perditini) incluye abejas solitarias de talla media. Este es el género hermano de Perdita (Michener, 2000), con el cual ha diversificado en el suroeste de los Estados Unidos de América y el centro y norte de México, asociados a la vegetación de zonas áridas y subtropicales (Danforth y Neff, 1992; Michener, 2000). En general, los Perditini son oligolécticos (Michener, 2007), como es el caso de la especie que aquí se estudia. Macrotera posee alrededor

Recibido: 07 abril 2009; aceptado: 19 agosto 2009 de 31 especies (Ayala et al., 1996), algunas de las cuales están presentes en áreas con vegetación subtropical a lo largo de la costa del Pacífico, como Macrotera pipiyolin (Snelling y Danforth, 1992) (Ayala et al., 1993). En la región de Chamela, los géneros Macrotera y Perdita están representados por 6 especies, 2 de las cuales, P. acapulcona Timberlake, 1954 y $P$. maritima Timberlake, 1954, habitan en áreas aledañas a playas y en dunas costeras, y el resto se encuentra en la selva baja caducifolia (Ayala, 1988), incluyendo a $M$. pipiyolin (Fig. 1), visitante de las flores de Opuntia excelsa Sánchez-Mejorada, 1972 (Snelling y Danforth, 1992).

Son pocos los estudios referentes a la biología de 


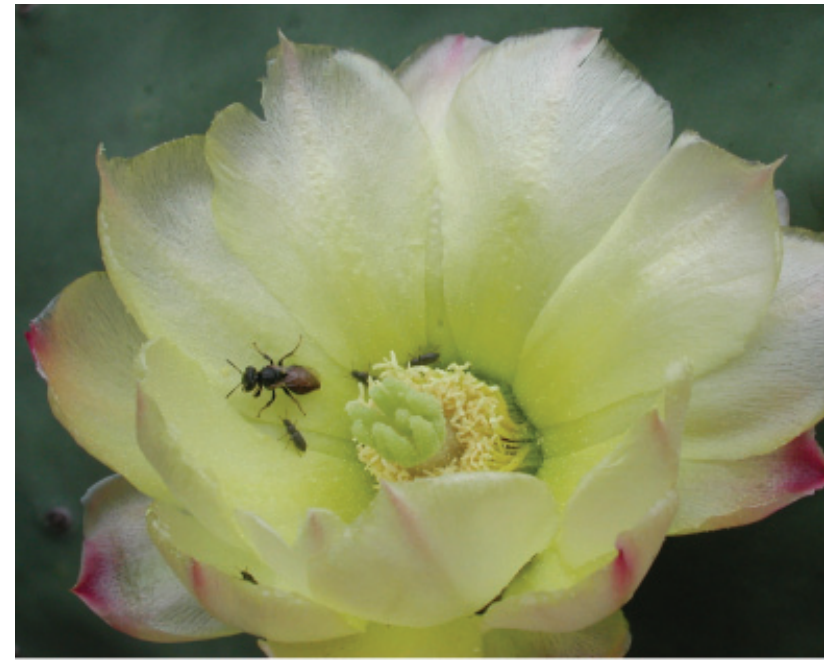

Figura 1. Macho dominante de Macrotera pipiyolin en espera de hembras sobre la flor de Opuntia excelsa.

especies de Macrotera. Los más completos son, sin duda, los de M. portalis Timberlake, 1954 y M. texana Cresson, 1878 (Rozen, 1971; Danforth, 1991; Neff y Danforth, 1992), donde también se tratan aspectos morfométricos y del dimorfismo de los machos. Por los anteriores estudios se sabe que algunas especies forman agregaciones de 4 a 10 nidos por sitio, que son compartidos por 2 o más hembras que construyen y aprovisionan sus propios nidos (Michener, 1974; Neff y Danforth, 1992).

Nuestro objetivo es aportar información sobre la historia natural de M. pipiyolin (Fig. 1), su actividad estacional, reproducción, biología de anidación, dimorfismo sexual y la planta de la cual obtiene sus recursos alimenticios.

\section{Material y métodos}

El estudio se llevó a cabo en la Estación de Biología Chamela, del Instituto de Biología, UNAM, situada en la costa del estado de Jalisco, municipio de la Huerta, entre los $19^{\circ} 30^{\prime}$ y $19^{\circ} 33^{\prime} \mathrm{N}$ y $105^{\circ} 00^{\prime}$ y $105^{\circ} 03^{\prime} \mathrm{O}$. La estación cubre una área de 3319 ha, con altitudes que van de 30 a 500 m (Bullock, 1988). Se caracteriza por su topografía irregular con lomeríos que originan numerosos sistemas de pequeñas cuencas (Cervantes et al., 1988). El clima de Chamela es de tipo Aw(x')i, el más seco de los cálidos subhúmedos, de acuerdo con el sistema Köppen (modificado por García, 1973; Bullock, 1986). La temperatura media anual es de $24.9^{\circ} \mathrm{C}$, con los meses más cálidos entre mayo y septiembre. La dinámica de lluvias origina 2 épocas marcadas; la húmeda de julio a noviembre y la seca de diciembre a junio (Bullock, 1986, 1988). La vegetación dominante es selva baja caducifolia, que está presente en los lomeríos con suelos someros, alcanzando una altura de 4 a $15 \mathrm{~m}$, con numerosas especies arbóreas que pierden sus hojas durante la época seca y un sotobosque bien desarrollado; algunas de las especies más comunes son Amphipterygium adstringens, Caesalpinia eriostachys, Cordia alliodora, Croton pseudoniveus, Lonchocarpus lanceolatus, Randia thurberi, Thouinia parvidentata y Trichilia trifolia (Lott, 1985; Bullock, 1988).

Las observaciones se realizaron durante 50 días de trabajo de campo, entre los meses de junio y agosto de 1994. Con anticipación al inicio de la temporada de lluvias y a la época de actividad de $M$. pipiyolin, se localizaron los posibles sitios de anidación y las áreas con Opuntia excelsa. Se dio seguimiento a la floración, al emerger de las abejas y a la actividad en los nidos en 4 sitios diferentes durante 15 días, de las 07:00 a las 17:00. Para el estudio de la actividad reproductiva se marcó el tórax de 26 machos y 23 hembras con esmalte de diferentes colores. A partir de observación directa, se registró la actividad de las hembras y machos sobre las flores, así como la presencia de otras especies de abejas Los datos de las observaciones se vaciaron en fichas, registrándose el número de hembras, machos y cópulas por periodos de media hora a partir de las 07:00 hasta las 17:00. Estas observaciones se llevaron a cabo durante 15 días. La actividad de las abejas en 18 nidos se registró tomando en cuenta los tiempos entre la salida y entrada de la abeja, anotando si regresaba con o sin polen.

Se estudió la arquitectura de 12 nidos mediante una modificación del método de Rozen y Buchmann (1990) y Rozen (1992), que consiste en inyectar yeso semilíquido por la entrada del nido para obtener la forma del túnel y seguirlo durante la excavación. Para la excavación se utilizó una pala de mano, una navaja suiza, una espátula y una manguera de plástico para eliminar el exceso de polvo y suelo soplando por ella. Las mediciones del nido se tomaron con una regla graduada en milímetros. Los nidos se dibujaron a escala sobre papel milimétrico.

Para estudiar el desarrollo de los estados inmaduros, se tomaron de 50 celdas los huevos y larvas, los cuales se pasaron a cápsulas de gelatina. En el laboratorio se colocaron en celdas labradas con cera en cajas de Petri, siguiendo el método de Michener (1953).

Con el fin de tipificar el dimorfismo sexual y el dimorfismo entre machos se realizó un análisis morfométrico como el usado por Danforth y Neff (1992). Para esto, se capturaron 58 abejas ( 35 machos y 23 hembras) sobre las flores con una red entomológica y se sacrificaron en cámaras letales con cianuro de potasio. Las mediciones de los ejemplares se realizaron con un microscopio estereoscópico con ocular con reglilla micrométrica. Se 
tomaron 8 medidas lineales; largo del ojo (LO), distancia entre mandíbulas (DIM), largo de la mandíbula (LM), longitud entre la parte superior de la cabeza y el margen anterior del ocelo medio (LPSC), longitud entre el margen anterior del ocelo medio y el margen anterior del clípeo (LOMC), longitud del ala anterior (LA), distancia intertegular (DIT) y longitud de la tibia trasera (LTT) (Fig. 2). El análisis estadístico se realizó con el programa StatView 4.1 (para equipos Macintosh).

Con el objeto de estimar la cantidad de polen que recolecta una hembra en cada viaje se recolectaron 18 hembras con cargas de polen cuando llegaban a sus nidos, éstas se conservaron en frascos con alcohol al 70\%. Para estimar la cantidad de polen presente en ambas escopas, se separaron 2000 granos de polen de Hibiscus, que son mucho más grandes que los de $O$. excelsa, lo que facilita su diferenciación en el conteo. El polen de Hibiscus fue teñido con fucsina ácida (una gota) y lavado con agua destilada. Los 2000 granos teñidos se integraron a la masa de polen de una celda (alimento para una cría) ( 5 celdas en total) o la carga de polen de las escopas de una abeja, en un vaso de precipitado de $80 \mathrm{ml}$ con $20 \mathrm{ml}$ de agua destilada. La muestra se homogenizó con un agitador magnético; con una pipeta se tomó una muestra, y una gota de ésta se colocó sobre un portaobjetos, para contar al microscopio

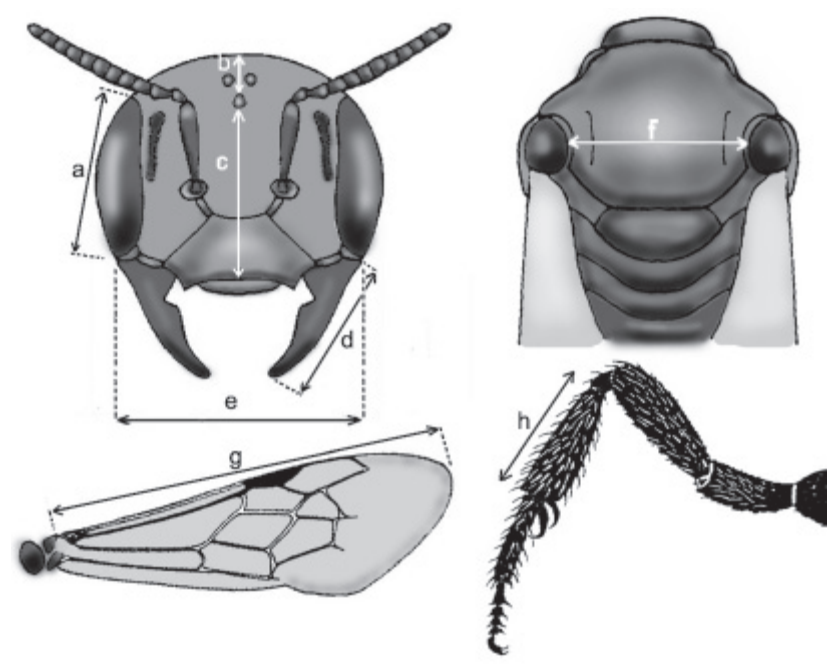

Figura 2. Medidas lineales de cabeza, tórax, ala y pata posterior de adultos de machos y hembras de Macrotera pipiyolin utilizadas en el análisis morfométrico: a) largo del ojo (LO), b)longitud entre la parte superior de la cabeza y el margen posterior del ocelo medio (LPSC), c) longitud entre el margen anterior del ocelo medio y el margen posterior del clípeo (LOMC), d) largo de la mandíbula (LM), e) distancia intermandibular (DIM), f) distancia intertegular (DIT), g) largo del ala (LA) y h) largo de la tibia trasera (LTT). los granos de polen teñidos y los de la abeja. Usando una proporción geométrica, se obtuvo el número de granos de polen existentes en cada muestra, para lo cual se realizaron conteos de distintas gotas de una muestra. Con el fin de obtener datos representativos, se analizó una varianza acumulada hasta que se estabilizó el análisis, para ello se graficó el resultado de la varianza acumulada y una vez que alcanzó la asíntota se dio por estabilizado el análisis.

\section{Resultados}

Los adultos de $M$. pipiyolin emergen poco después del inicio de la temporada de lluvias. Su emergencia se encuentra asociada con la floración de $O$. excelsa, planta de la que obtienen tanto el néctar como el polen, recursos que requiere la abeja y las crías. Es un visitante especialista (monoléctico) sobre esta cactácea, considerando que tanto en las escopas como en las celdas únicamente se encontró polen de la misma. Esta especie inicia la floración a mediados de junio y culmina entre los últimos días de julio y primeros de agosto, presentando su pico de floración entre los últimos días de junio y alrededor del 20 de julio. La actividad y emergencia de los adultos comienzan con las primeras lluvias y se registraron a partir del 29 de junio, posiblemente 1 o 2 días después de su inicio. El 6 de julio se registró la mayor cantidad de hembras y machos sobre las flores; a partir de esa fecha, su número comenzó a disminuir. Para el 18 de julio se observó una fuerte caída de la actividad sobre las flores y el 26 del mismo mes fueron ya muy pocos los individuos activos; sin embargo, en los primeros días de agosto aún se observaron algunas abejas; se considera que la actividad de los adultos es aproximadamente de 35 días (Fig. 3).

Estrategias reproductivas. Los machos pasan la noche en las flores de O. excelsa. Entre 08:30 y 09:30 realizan vuelos de inspección para elegir la flor donde pasarán el día: para ésto, visitan varias flores de la misma planta y en cada flor realizan algo parecido a una inspección. Una vez hecha su elección, permanecen en la flor en espera de las hembras. En las flores se reúnen varios machos, formando grupos de 4 a 9 individuos. Aparentemente hay machos con comportamiento dominante, subordinado o de patrulleo, estrategia que mantienen durante su vida como adultos y que es más evidente durante los días con mayor abundancia de individuos. Los machos dominantes se distinguen por una conducta al parecer más activa y agresiva que la del resto de los machos; realizan recorridos en la flor y tienen frecuentes interacciones con los machos subordinados, a los cuales mantienen fuera del centro de ésta; cuando una hembra llega a la flor, el dominante parece tener preferencia sobre los otros machos, así que es el primero en tomarla. 


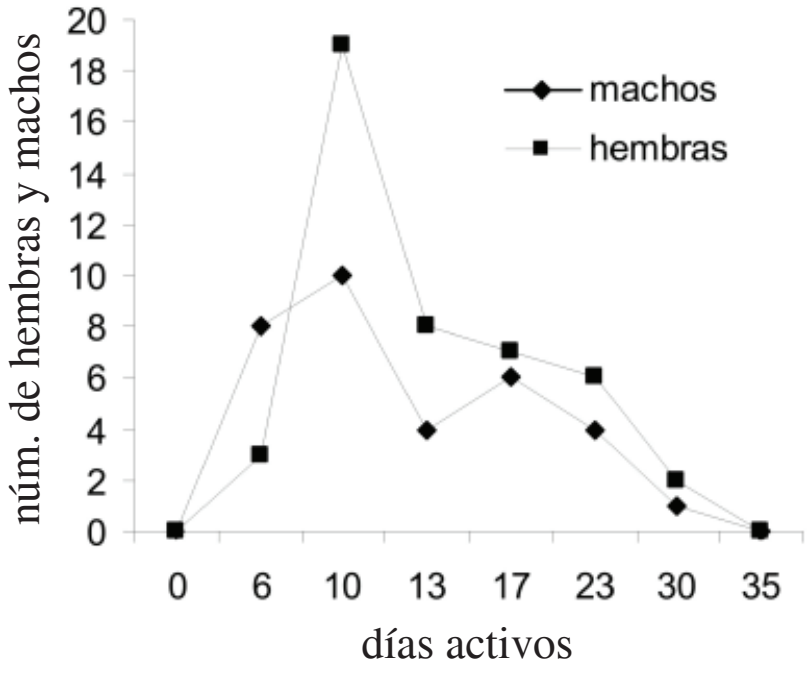

Figura 3. Media del número de machos y hembras sobre las flores por intervalos de 30 minutos durante los 35 días de actividad de Macrotera pipiyolin.

Los machos subordinados pasan más tiempo en reposo entre los pétalos y se muestran menos agresivos; sin embargo, entre éstos se presentan también interacciones, durante las cuales se sujetan de las mandíbulas y realizan giros con incursiones por el interior de la flor. Los machos patrulleros vuelan entre las flores, aparentemente en busca de hembras disponibles para aparearse; cuando uno de ellos se posa en una flor, el dominante o alguno de los subordinados lo expulsa. En ocasiones, los machos patrulleros pueden desplazar al macho dominante de una flor, cambiando de esta forma su estrategia de búsqueda. Durante la mañana, las interacciones entre machos son muy frecuentes, pero después de las 13:00 horas disminuyen y se mantienen por más tiempo entre los pétalos, adoptando una posición con el extremo posterior del abdomen hacia la base de la flor. Es posible que esta actitud pasiva se deba a que ya se establecieron en la flor en la que reposarán el resto del día y la noche, y la actividad de las hembras sobre las flores ha disminuido casi en su totalidad. Un rasgo característico de machos y hembras es que despiden un olor fuerte, perceptible para el olfato humano, que posiblemente se deba a feromonas.

Cópulas. Los machos son polígamos y las hembras poliándricas. Los apareamientos se registraron durante todo el periodo de actividad, con un pico máximo alrededor del 13 de julio, después se observó una disminución hasta el 30 de julio, cuando la actividad prácticamente llegó a su fin (Fig. 4). Los machos no muestran comportamiento de cortejo, cuando las hembras llegan a las flores, simplemente son sujetadas por éstos. Las hembras pueden copular

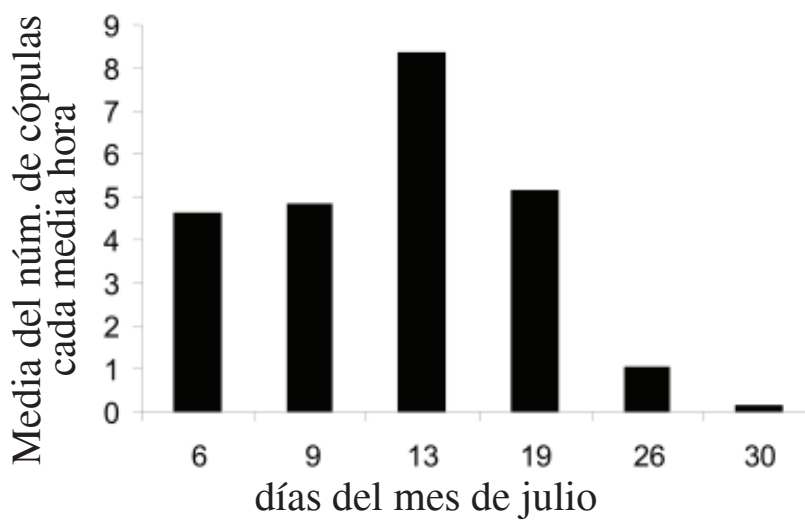

Figura 4. Media del número de cópulas registradas por intervalos de 30 minutos durante el periodo de actividad de los adultos de Macrotera pipiyolin.

varias veces con el mismo o diferente macho durante su visita a una flor. Durante la cópula el macho sujeta con sus mandíbulas a la hembra entre el tórax y el abdomen y toma con su primer par de patas el abdomen de ésta, el macho coloca sus alas hacia atrás paralelas a su cuerpo, la hembra extiende sus alas hacia los lados formando una cruz y se mantiene sujeta a la flor con sus patas. Es frecuente ver que las hembras continúan el forrajeo mientras se mantienen en cópula. Cuando las cópulas son largas, hembra y macho se mueven hacia los pétalos, resguardándose entre éstos, donde permanecen hasta que finaliza el evento. En ocasiones, durante la cópula, un segundo macho sujeta al que se está apareando, el cual se deshace del segundo con sus patas traseras. Esta conducta podría ser considerada como una disputa por la hembra o que se trate de una confusión en la búsqueda de hembras. Las cópulas duran de unos cuantos segundos hasta más de una hora. Al concluir la cópula, los machos inician una actividad de aseo, limpiando con sus patas tanto su cabeza como el resto del cuerpo y alas, mientras que las hembras usualmente siguen con el forrajeo.

Nidos. Las agregaciones se encontraron ubicadas en las veredas dentro de la estación, en lugares abiertos con escasa o nula vegetación con pocas piedras pequeñas; algunos de los sitios presentan un poco de hojarasca. Con frecuencia, los nidos se ubican cerca de las plantas de O. excelsa. El suelo donde las abejas construyen sus nidos es duro y compacto, con granos finos. Las hembras no son selectivas del color del suelo; las agregaciones se localizaron tanto en suelos de color rojizo, determinado en las tablas Munsell como 7.5 y R 3/3, con una textura de franco a arcillo-arenosa y baja densidad de raíces, como en suelos pardos del tipo 10 y $\mathrm{R} 3 / 2$, con una textura de franco fina a franco limosa y con una densidad de raíces 
muy alta.

Las hembras persisten en los sitios con nidos pero no reutilizan nidos maternos. Los primeros fueron construidos desde los primeros días de julio entre las 12:00 y 15:00. En la búsqueda del sitio para establecer un nuevo nido, las hembras vuelan inspeccionando una área de aproximadamente 1 metro cuadrado, revisando repetidamente el lugar con vuelos rápidos. Una vez seleccionado el sitio, se posan e inspeccionan el suelo en el punto que eligen para excavar. En ocasiones, después de revisar una área la abandonan en busca de otros sitios. Luego que la abeja inicia la excavación, durante un lapso de 10 a 15 minutos extrae del interior del túnel pequeños túmulos de suelo con los que posteriormente tapa la entrada. $\mathrm{Al}$ inicio del día, cuando la hembra sale por primera vez, realiza un vuelo en forma de 8 sobre el nido. Este primer vuelo es más prolongado que los realizados durante el resto del día, y posiblemente tiene por objeto memorizar la posición y entrada del nido. Se puede considerar que la distribución de los nidos es gregaria siguiendo los criterios de Alcock et al. (1978), quienes indican que cuando una persona puede ver fácilmente por lo menos 10 entradas de nidos activos, la distribución de los mismos se considera gregaria, y si sólo puede observar menos de esa cantidad, es dispersa. En una misma área se pueden observar varias agregaciones bien definidas; en la parte central los nidos están muy cercanos entre sí y en la periferia la distancia se hace mayor.

Los nidos son simples, con una entrada circular con un diámetro de $5 \mathrm{~mm}(\mathrm{n}=12)$, no presentan chimeneas, pero sí un promontorio con un diámetro aproximado de $5 \mathrm{~cm}$ y una altura de alrededor de $1 \mathrm{~cm}$ (Fig. 5). La entrada se continúa en un túnel principal que alcanza una profundidad de hasta $12.9 \mathrm{~cm}$, pero algunos nidos logran sólo $4.6 \mathrm{~cm}$, siendo la media de $9.16 \mathrm{~cm}(\mathrm{n}=12)$. El túnel principal es simple, no presenta antecámaras ni túneles laterales definidos y por lo regular termina en una celda. Usualmente el túnel principal es vertical o un poco inclinado; la unión de las celdas con el túnel principal se pierde, sólo el túnel principal tiene en su interior una ligera película brillosa, en apariencia una sustancia impermeabilizante que da a sus paredes una consistencia más rígida; sin embargo, las conexiones con las celdas no presentan dicha sustancia y son rellenadas con suelo por la abeja (Fig. 5). Las celdas son ovaladas (Fig. 5) con una longitud de 9.9 a $10.4 \mathrm{~mm}$ (media 10.3 $\mathrm{mm}, \mathrm{n}=9$ ) y un ancho de 4.5 a $5.2 \mathrm{~mm}$ (media $4.9 \mathrm{~mm}, \mathrm{n}$ =7); el diámetro de la parte media oscila de 5.1 a $6.3 \mathrm{~mm}$ (media $5.1 \mathrm{~mm}, \mathrm{n}=8$ ) y en la parte más ancha de 5.2 a 6.3 $\mathrm{mm}$ (media $6.01 \mathrm{~mm}, \mathrm{n}=8$ ). Las celdas no se encuentran comunicadas entre sí y están dispuestas en un ángulo de $28^{\circ}$ respecto a la horizontal, aunque en algunas, el ángulo varía entre 11 y $25^{\circ}$. Las paredes de las celdas parecen
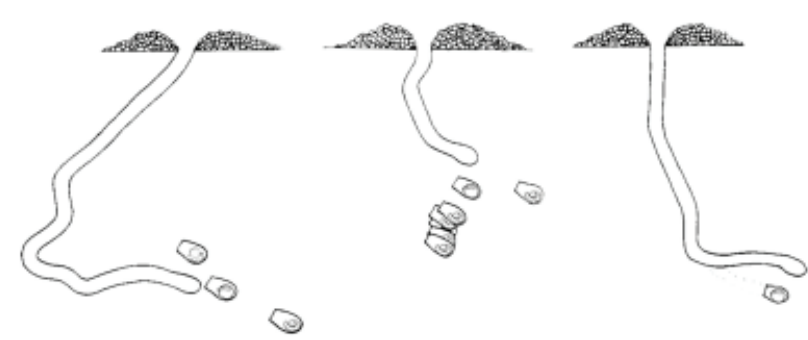

Figura 5. Características de la arquitectura interna de 3 nidos de Macrotera pipiyolin, en los que es posible ver el túmulo de suelo en la entrada, así como las celdas sin conexión evidente con el túnel principal.

estar cubiertas por una sustancia impermeabilizante, posiblemente la misma que presenta el túnel principal. Las celdas presentan un tapón elaborado con suelo de textura granulosa, que no parece impermeabilizado, de $4.6 \mathrm{~mm}$ de diámetro.

Actividad en flores. Macrotera pipiyolin es una especie monoléctica en la región de Chamela, Jalisco. Obtiene su alimento y el de su crías de las flores de O. excelsa, una especie de nopal con distribución limitada a una franja angosta a lo largo del litoral del Pacífico, entre el río Tomatlán, Jalisco y las inmediaciones de Barra de Navidad, Colima, siempre a una altitud menor de $200 \mathrm{~m}$. Esta Opuntia se ha registrado en múltiples localidades entre Barra de Navidad y Puerto Vallarta (Bravo-Hollis, 1978). Las flores son amarillas, grandes y generalmente abren después de las 08:30 y cierran después de las 14:00 si reciben la luz directa del sol, las flores que se encuentran en áreas sombreadas abren más tarde y cierran después de las 15:00. Cuando el polen de las flores es removido y la flor está por cerrar, el color de los pétalos se torna rojizo o rosado. En el área de estudio, estas flores también las visitan otras especies especialistas: Diadasia knabiana Cockerell, 1917 (Guardado, 1996) y Lithurgus bitorulosus Snelling, 1986, que son abejas más grandes y que pueden volar mayores distancias; estas abejas también obtienen el polen y su néctar sólo de esta planta, aunque L. bitorulosus tiene un periodo de vida más largo y visita otras especies de cactáceas que florecen en otras épocas del año; entre éstas $O$. puberula Pfeiffer, 1837, la otra especie de nopal presente en la región.

Las hembras inician su actividad de forrajeo sobre las flores alrededor de las 08:30 y dejan de visitarlas entre las 14:00 y 15:30. La temperatura y luminosidad parecen influir en las visitas de las hembras a las flores, ya que la actividad de estas abejas se incrementa al aumentar estas 2 variables durante las primeras horas del día, entre 09:30 y 11:30, cuando la actividad alcanza su pico más alto. 
Posteriormente, la actividad sufre un decremento paulatino, que culmina con el cese de la actividad entre las 14:30 y 15:00. Durante las visitas a las flores, las hembras se posan sobre los pétalos, el estigma o los estambres, en ocasiones se observa que la hembra recorre varios puntos de la flor antes de recolectar alimento. En general, colectan el polen de los estambres y lo colocan en las escopas; también remueven el polen adherido a su cuerpo y lo depositan en sus escopas. Se registraron algunos casos en que las hembras extraen el polen de las escopas de D. knabiana. El tiempo que la abeja invierte en obtener el polen de la flor de $O$. excelsa, en cada una de sus visitas es muy variable (6.32-29.93 seg.; media 14.92 seg., $\mathrm{n}=32$ ).

Actividad en nidos. La actividad de aprovisionamiento del nido se lleva a cabo entre las 09:00 y 14:00. Se registró la hora de salida y de regreso de la abeja con el fin de mostrar los patrones de actividad en los nidos (Fig. 6). El tiempo que la abeja pasa fuera del nido lo invierte en visitar flores de $O$. excelsa, fuente de polen y néctar para el aprovisionamiento de sus celdas, y donde también se presentan los encuentros con los machos con propósitos reproductivos. Cuando la abeja permanece dentro del nido, al parecer prepara las celdas o simplemente deposita el polen en ellas. Es posible que parte de este tiempo lo requieran para preparar las celdas, impermeabilizarlas, pulirlas, formar las bolas de polen, oviposicionar $y$ tapar las celdas. Se registró variación en los patrones de actividad de las hembras que anidan en una agregación, bajo las mismas condiciones ambientales (temperatura y luminosidad). La mayoría de los individuos están ya

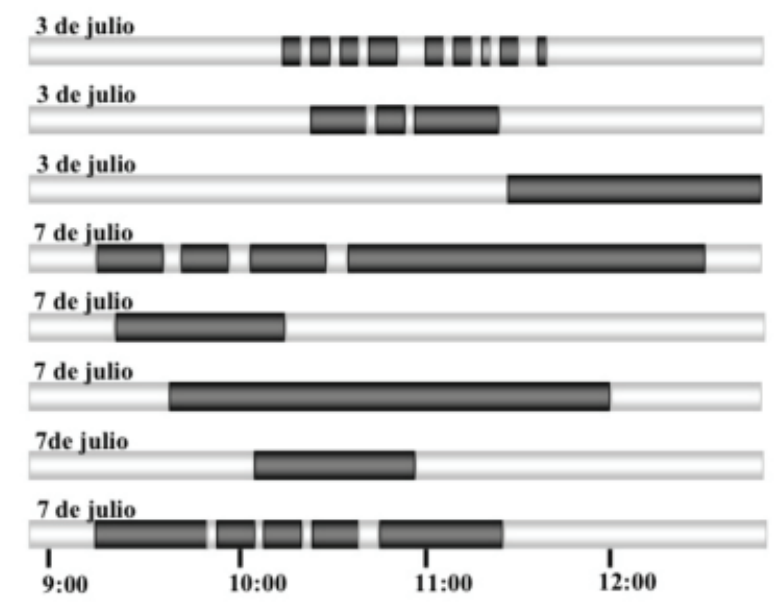

Figura 6. Patrones de actividad de Macrotera pipiyolin en los nidos a partir del registro de salidas y entradas de las hembras a sus nidos. Los segmentos obscuros de la barras muestran el tiempo que las hembras pasan fuera del nido y los blancos, el tiempo que permanecen dentro del nido durante el día. activos después de las 09:00. Las hembras realizan de 1 a 10 salidas por día, con una media de $3.5(n=18)$; por lo general regresan con cargas de polen de tamaño variable. De tal forma, para determinar la cantidad de viajes que se necesitan para aprovisionar una celda, se considera que la masa de polen contiene alrededor de 76000 granos $(n=5)$ y que las hembras acarrean en sus escopas un número de granos que va de 4300 a $38000(n=18)$, lo que significa que para aprovisionar una celda, la hembra puede ocupar de 2-18 viajes.

Estados inmaduros. Los huevos son alargados y curvos, con los extremos redondeados, uno de éstos más agudo que el otro (Fig. 7A). Son blanquecinos hialinos con integumento brillante. Miden en promedio $2.6 \mathrm{~mm}$ de longitud y un ancho de $0.98 \mathrm{~mm}(\mathrm{n}=3)$. El huevo es insertado en la masa de polen, de manera que se mantenga firme en la base de ésta. La masa de alimento es esférica. Los huevos son extremadamente delicados y frágiles.

El desarrollo larvario consiste en 3 etapas, predefecación, defecación y posdefecación (Michener, 1974), dado que no se puede registrar con certeza el número de estadios. El periodo que transcurre de huevo a larva en posdefecación, es de aproximadamente 30 días. La predefecación representa el paso de huevo a larva juvenil y es el periodo durante el cual la larva se alimenta más activamente y cuando presenta más cambios en su tamaño (Fig. 7B). En un principio, la larva es blanquecina hialina pero conforme crece y se alimenta su cuerpo se torna amarillento. Sus primeros 5 tubérculos tienen un ancho de $0.045 \mathrm{~mm}$ y los siguientes 3 de $0.054 \mathrm{~mm}$, el noveno y décimo de $0.036 \mathrm{~mm}$ y los restantes de $0.018 \mathrm{~mm}$. Al llegar al estadio de defecación la larva ha adquirido su máximo tamaño (Fig. 7C) y comienza a defecar, depositando las heces uniformemente sobre la superficie superior de la celda, o sea, la que está sobre su abdomen; las excretas son amarillentas y tienen forma de fragmentos subcilíndricos, cada fragmento está unido al otro por medio de un hilo muy delgado de material sedoso. La posdefecación se inicia cuando la larva ha dejado de defecar y su integumento se torna rígido y anaranjado pálido, su cuerpo se contrae en dirección dorsoventral y se mantiene inmóvil (Fig. 7D). Presenta 12 pares de tubérculos de tamaño similar, excepto los últimos 3 que son más pequeños. La abeja permanece en este estado alrededor de 10 meses y medio, antes de comenzar a sufrir nuevos cambios para transformarse en pupa. Se observan 10 espiráculos al igual que en las etapas larvales previas (Figs.7B, C, D). El integumento de la cabeza no está esclerosado, excepto en el ápice de las mandíbulas y maxilas. El tamaño de la cabeza es moderado con respecto al tamaño del cuerpo, con una longitud de $0.227 \mathrm{~mm}$ y un ancho a la altura de las maxilas de 0.136 $\mathrm{mm}$ (Fig. 7E, F). Los orificios tentoriales anteriores se 
encuentran al comienzo de la sutura epistomal. Presenta bandas parietales rectas y antenas formadas por elevaciones redondeadas, que están sobre una área globosa, con superficie irregular con pequeñas verrugas. El clípeo con longitud y ancho similar, la sutura epistomal no está bien definida, pero se distingue una pequeña elevación en su parte media. El labro tiene un ancho mayor a una vez y media su longitud, y presenta 2 tubérculos labrales. Las mandíbulas son anchas en su base y tienen un extremo distal cónico, el ápice es pardo oscuro, las maxilas son más largas que anchas. El labio presenta un ápice redondeado, entre los palpos labiales se encuentra la abertura salival que se observa como una línea en forma de media luna (Fig. 7E).

La pupa es muy semejante a la abeja adulta; cuando joven, blanquecina hialina y con estructuras aún no bien desarrolladas (Fig. 7G). El integumento cambia según va madurando y adquiere gradualmente tonos más oscuros, desde amarillo tenue, anaranjado tenue, pardo claro, pardo oscuro, hasta negruzco. La cabeza presenta integumento sin sedas, espículas o tubérculos, las antenas no presentan tubérculos. Tiene ocelos evidentes. Los ojos y el ápice de las mandíbulas son los primeros en pigmentarse. Las partes bucales también son evidentes, con la glosa tan larga como la mitad de la longitud del cuerpo, aún no se aprecia el flabelo (Fig. 7G). El mesosoma presenta integumento sin sedas o espinas. El lóbulo del pronoto está redondeado en el ápice. El mesoscuto presenta 1 tubérculo en la parte media posterior, al igual que el escutelo, 1 tubérculo en la parte media, el resto del mesosoma sin tubérculos. Procoxas, mesocoxas y metacoxas con proyecciones alargadas agudas apicales, las proyecciones de las procoxas un poco más largas que las de las mesocoxas y metacoxas. Los trocánteres con proyecciones espiciformes, con las bases anchas (Fig. 7G). El metasoma en vista dorsal, consiste en 6 o 7 terguitos según el sexo, en las hembras con ovipositor visible (el aguijón). Los terguitos 1-4 con una línea de espinas pequeñas a lo largo de la parte superior del margen posterior (Fig. 7G).

Dimorfismo sexual. Los adultos presentan un claro dimorfismo sexual. Un análisis morfométrico de los adultos de los 2 sexos muestra diferencias significativas usando 8 mediciones lineales (véase metodología y Fig. 2). Al comparar individuos de distinto sexo, usando una prueba de t-Student para LM, LO, DIM, LOMC y LTT se obtuvo una significancia de 0 , para DIT de 0.001, para LPSC de 0.003 y para LA de 0.005 , lo que muestra una clara diferencia entre los sexos. Los sexos también pueden diferenciarse por el color; en las hembras el integumento es oscuro con líneas transversales pardas en los terguitos metasomales; los machos presentan abdomen anaranjado rojizo, y el resto del cuerpo más oscuro. Los machos

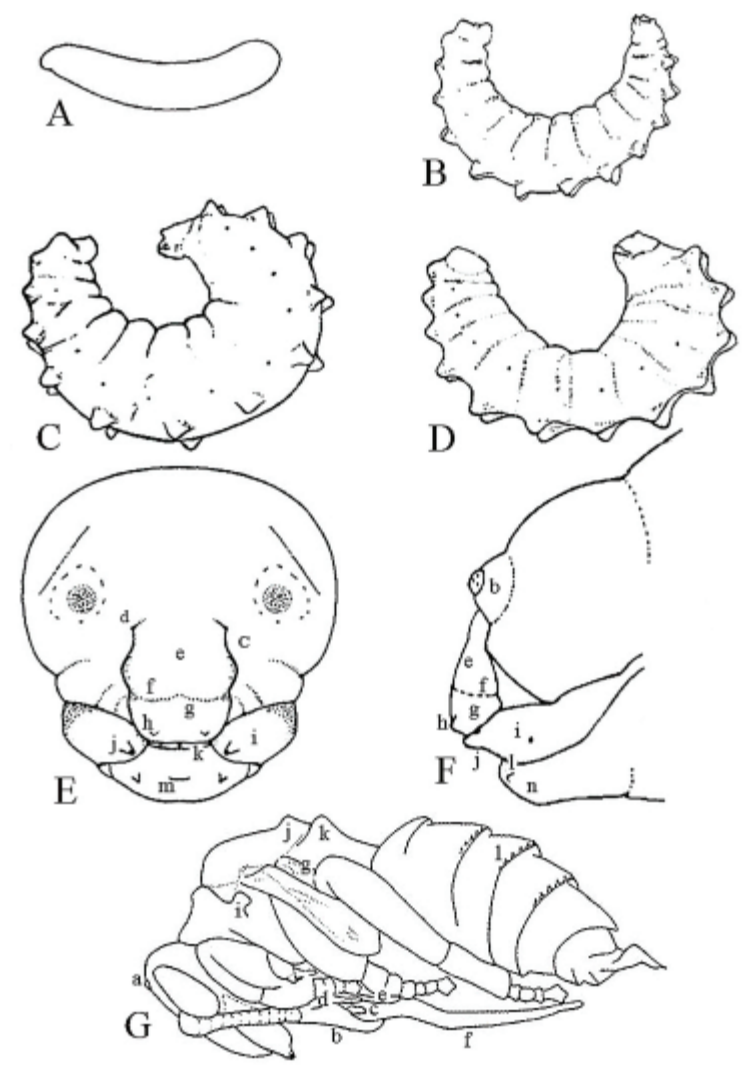

Figura 7. Estados inmaduros de Macrotera pipiyolin. A) huevo; B) larva en estado predefecatorio; C) larva en estado defecatorio; D) larva en estado posdefecatorio; E) y F) cabeza de larva posdefecatoria, vista de frente y lateral; a, banda parietal; b, antena; c, sutura epistomal; d, orificio tentorial anterior; e, clípeo; f, sutura labroclípeal, g, labio, h, tubérculo labial; i, maxilas; j, palpo maxilar; $\mathrm{k}$, mandíbula; 1 , palpos labiales; $\mathrm{m}$, abertura salival; n, labio; G) pupa; a, ocelo; b, galea; c, paraglosa; d, palpos maxilares; e, palpos labiales; f, glosa; g, proyección del trocanter; h, proyección de la coxa; i, lóbulo del pronoto; j, tubérculo del mesoscuto; $\mathrm{k}$, tubérculo del escutelo y $\mathrm{l}$, espinas.

presentan mayor variación de su talla que las hembras, lo cual pareciera relacionarse con el comportamiento reproductivo. En el análisis morfométrico, comparando entre los machos que adoptan la estrategia reproductiva de dominantes y subordinados, usando $\mathrm{t}$ Student, se encontraron diferencias significativas en las siguientes medidas: DIM de 0.010, LTT de 0.028 y LA de 0.035 . Pero no para LM 0.068, LO 0.072, LOMC 0.112, LPSC 0.298 y DIT 0.893. Como dato relevante, se registró una mayor variación de las tallas en machos subordinados que entre los dominantes. No se registró evidencia de depredación o parásitos, pero es posible que las abejas que visitan las flores estén expuestas a depredadores como aves, arañas u otros insectos. Sólo se registraron hormigas oportunistas, Ectatomma ruidum y Pheidole sp., sustrayendo polen de los nidos de $M$. pipiyolin, no se observó ningún parásito en 
los nidos y/o atacando las larvas o adultos.

\section{Discusión}

Los adultos iniciaron su emergencia de los nidos poco después de las primeras lluvias en los últimos días del mes de junio; a principios de julio se observaron activas la mayoría de las abejas, la emergencia y su periodo activo coincide con la floración de $O$. excelsa, planta de donde obtiene su alimento. Ésta es una cualidad de algunos organismos para sincronizar su vida a la estacionalidad (Thornill y Alcock, 1983, Tauber et al., 1986). Como ocurre en otros Perditini, esta especie es oligoléctica y, por los muestreos exhaustivos de abejas realizados sobre flores en la región de Chamela (Ayala, 1988, 2004), así como por el polen observado en las escopas y en la celdas, que corresponde sólo al de $O$. excelsa, puede considerarse monoléctica y estrechamente asociada a la floración de esta Opuntia, al menos en la región de Chamela. Macrotera pipiyolin presenta una sola generación al año (univoltina) y su periodo de vida como adulto es aproximadamente de 35 días. En contraste con otras especies de Macrotera o Perdita que han sido estudiadas, $M$. pipiyolin presenta un periodo de actividad estacional que puede considerarse corto en comparación con $P$. octomaculata Dalla Torre, 1896 que está activa hasta por 98 días entre julio y octubre en los estados de Nueva York y Nueva Inglaterra (Timberlake, 1960) y P. halictoides Smith, 1853 con 139 días de actividad entre marzo y julio en Florida, y 109 días de actividad de junio a octubre en otros lugares del medio oeste estadounidense (Timberlake, 1958, 1960). Macrotera texana tiene un periodo similar al de $M$. pipiyolin, está activa en mayo en el centro de Texas sólo durante 3 semanas aproximadamente, aunque algunos individuos pueden vivir hasta 28 días (Neff y Danforth, 1992).

El comportamiento reproductivo de los machos de abejas presenta diferencias entre géneros, pero las 2 estrategias fundamentales son buscar o esperar. Los machos de $M$. pipiyolin presentan al menos 3 diferentes estrategias reproductivas, macho dominante, subordinado y patrullero. Una posible explicación del porqué de estos 3 tipos de comportamiento en machos, puede ser las ventajas que obtienen, independientemente del gasto de energía. Los machos dominantes, al parecer, obtienen mayor número de hembras; sin embargo, la defensa de una área con implicaciones en el potencial reproductivo también tiene un costo energético (Alcock et al., 1977). A pesar de que los machos dominantes parecen tener la posibilidad de expulsar de la flor a los subordinados, no lo hacen; quizá porque esta estrategia esté relacionada con las observaciones que realizaron Alcock et al. (1978) en los machos de algunas especies de abejas y avispas. Estos autores encontraron que en ocasiones las hembras son más atraídas por los sitios donde hay grupos de machos que por un macho solitario. Una conducta similar se registró para $M$. pipiyolin en una planta de $O$. excelsa que presentaba 1 o 2 flores donde no se establecían machos, o sólo llegaban por periodos muy cortos; así también, rara vez estas flores fueron visitadas por las hembras. El color anaranjado rojizo del metasoma de los machos puede estar relacionado con esta conducta, al ser muy contrastante con el amarillo de la flor (Fig. 1), lo cual puede atraer la atención de las hembras, favoreciendo con esto la actividad reproductiva. Otro factor a considerar es el olor que despiden tanto hembras como machos, el cual puede funcionar como un atrayente; así, si en una flor no se establecen machos, no existe olor que atraiga a otros machos para formar grupos o a hembras, por lo tanto la flor será pocas veces visitada. En apariencia, los machos subordinados obtienen menos hembras que los dominantes, pero invierten menos esfuerzo que éstos, ya que pasan gran parte del tiempo entre los pétalos esperando la llegada de hembras. Se observan machos con un comportamiento alternativo de patrulleo que visitan flores provocando enfrentamientos con los dominantes a los cuales suplantan en ocasiones. Los machos patrulleros, durante sus visitas a las flores, encuentran hembras ocupadas en el pecoreo sobre la flor, con las cuales copulan, de manera que su gasto de energía se invierte en patrullar y no en la defensa de sitios.

Las hembras de $M$. pipiyolin son poliándricas. Alcock et al. (1978) proponen que varias inseminaciones puede tener ventajas dado que aseguran un adecuado suplemento de esperma, seguridad de que se adquiere esperma funcional, disminución de los costos fisiológicos asociados con mantener una gran espermateca y el esperma por un tiempo prolongado, permite también adquirir nutrientes presentes en el esperma, genera variaciones genéticas en la descendencia (Lin y Michener, 1972) y optimiza el tiempo y energía requerida para resistir los embates de los machos. Para construir sus nidos M. pipiyolin escoge sitios cercanos a las plantas de $O$. excelsa de las que obtiene su alimento; son nidos simples, con celdas independientes, que pierden conexión con el túnel principal; al parecer, las hembras los rellenan con suelo, lo cual puede ser una estrategia que permite disminuir el ataque de posibles parásitos o depredadores.

Los nidos de esta especie son más simples que los de otras especies del mismo género, aunque con dimensiones similares. En especies de Macrotera y Perdita pueden, o no, presentar túneles laterales y varias entradas, como en P. difficilis Timberlake, 1964 y P. luciae Cockerell 1899, que son más profundos que los que aquí se describen (Danforth, 1989). Los nidos de P. texana tienen muchas 
ramificaciones y una profundidad entre 10 y $15 \mathrm{~cm}$ (Neff y Danforth, 1992). Para el aprovisionamiento de las celdas, las hembras dependen de las flores de $O$. excelsa y su actividad diurna no parece estar relacionada con la temperatura o luminosidad, de tal forma, que se observan diferentes patrones de actividad de las hembras de una agregación de nidos que están bajo la influencia de las mismas condiciones ambientales. En general, la actividad diurna en la zona de estudio ocurre entre las 8:30 y 14:00. La actividad de aprovisionamiento en los nidos posiblemente está afectada por el comportamiento reproductivo en las flores, dado que las cópulas pueden durar de unos cuantos segundos hasta más de una hora, lo que puede influir en el tiempo que la abeja permanece fuera del nido. Las hembras pueden acarrear en sus escopas una cantidad variable de polen, que va de 4300 hasta 38 000 granos. Esta variabilidad puede ser resultado de la falta de polen en las flores o su conducta reproductiva. De esta forma, se requieren de 2 a 18 viajes para completar la masa de polen con un volumen suficiente para que una cría complete su desarrollo. Si consideramos que hay 18 días de actividad máxima, y por día realizan en promedio 5 viajes por polen, durante su vida una hembra puede lograr entre 6 y 45 crías.

La larva de $M$. pipiyolin es similar a la de otros panurginos, con tubérculos dorsales en los segmentos, lo que le sirven para mantener el polen fuera del contacto de las paredes de la celda mientras se alimenta (Eickwort, 1977). La pupa es similar a la de P. octomaculata Say, 1824, que presenta también unas proyecciones en las procoxas, mesocoxas y metacoxas, y proyecciones a manera de espinas gruesas en los 3 pares de trocánteres. Es posible que el desarrollo de los estados inmaduros esté relacionado con la variación de los factores ambientales (temperatura, luz y humedad); sin embargo, las larvas de M. pipiyolin en estado de prepupa que se mantuvieron en el laboratorio en condiciones no controladas de temperatura cambiaron a pupas y adultos al mismo tiempo que los individuos en el campo, lo que sugiere, que la especie no basa su emergencia en las condiciones ambientales sino en alguna forma de reloj biológico.

En Hymenoptera hay muchos ejemplos donde se observa que los machos de una misma población adoptan 2 o más estrategias reproductivas (Alcock et al., 1978; Thornhill y Alcock, 1983), lo que puede involucrar la defensa agresiva de un territorio y una conducta no territorial (Austand, 1984; Dominey, 1984); los individuos adoptan una de estas estrategias dependiendo de sus características físicas como adultos, como el tamaño del cuerpo, de sus mandíbulas y cabeza o su coloración; por otra parte, los adultos pueden cambiar de estrategia durante su vida (Alcock et al., 1977).
Macrotera texana, de acuerdo con Danforth y Neff (1992), se puede considerar precursora de un dimorfismo asociado a la reproducción, en el cual la variación de los machos es tanto morfológica como conductual. Algo similar ocurre con los machos de M. portalis, donde unos son capaces de volar y tienen una cabeza pequeña, por lo que pasan su tiempo en las flores; otros, presentan una cabeza muy grande que no les permite volar y, por lo tanto, permanecen en los nidos (Danforth, 1991). Los machos de $M$. pipiyolin muestran también variación morfológica que posiblemente repercute en sus estrategias reproductivas. El análisis morfométrico demostró que las medidas del largo de la tibia trasera, largo del ala y la distancia intermandibular tienen una diferencia palpable entre los grupos de machos, siendo los dominantes los que registran las tallas mayores. La distancia intermandibular, puede ser una de las variables más importantes ya que los machos utilizan sus mandíbulas para sujetar a las hembras durante las cópulas, el hecho de que ésta sea mayor en los dominantes puede favorecer a que éste pueda copular con un mayor número de hembras, al poder sujetar hembras de diferentes tallas; posiblemente esta característica también le favorezca en los encuentros con otros machos. Alas más largas pueden ayudar en la rapidez del encuentro con la hembra; y patas traseras más grandes puede influir en el sostén y defensa de la hembra durante la cópula, ya que en varias ocasiones se observó que machos en cópula eran sujetados por otros y el primero de deshacía de ellos con sus patas traseras.

Esta especie de Macrotera resulta ser parte de un sistema de especies que dependen de $O$. excelsa, nopal endémico de la costa de Jalisco que permite la sobrevivencia de una fauna de abejas que incluye especies de Diadasia, Lithurgus, Asmeadiella y meliponinos (Ayala, 2004), así como colibrís (Arizmendi y Ornelas, 1990) que al mismo tiempo polinizan y permiten la reproducción de esta magnífica cactácea.

\section{Agradecimientos}

Al personal de la Estación de Biología Chamela (IBUNAM) por las facilidades brindadas y que hicieron posible la realización de este estudio. A Enrique González por sus sugerencias y comentarios a nuestro trabajo.

\section{Literatura citada}

Alcock, J., C. E. Jones y S. L. Buchmann. 1977. Male mating strategies in the bees Centris pallida Fox (Hymenoptera: Anthophoridae). The American Naturalist 111:145-155. 
Alcock, J., E. M. Barrows, G. Gordh, L. Hubbard, L. L. Kirkendall, D. Pyle. T. L. Ponder y F. G. Zalom. 1978. The ecology and evolution of male reproductive behavior in the bees and wasps. Zoological Journal of the Linnaean Society 64:293-326.

Austand, S. N. 1984. A classification of alternative reproductive behaviors and methods for field-testing ESS models. American Zoologist 23:309-319.

Ayala, R. 1988. Abejas silvestres (Hymenoptera: Apoidea) de Chamela, Jalisco, México. Folia Entomológica Mexicana 77: 395-493.

Arizmendi, M. C. y F. Ornelas. 1990. Hummingbirds and their floral resources in a tropical dry forest in México. Biotropica 22:172-180.

Ayala, R. 1988-1989. La fauna de abejas silvestres (Hymenoptera; Apoidea) de Chamela, Jalisco. México. Folia Entomológica Mexicana 77:395-93.

Ayala, R., T. L. Griswold y S. H. Bullock. 1993. The native bees of Mexico. In Biological diversity of Mexico: origins and distribution, T. P. Ramamoorthy, R. Bye, A. Lot y J. Fa (eds.). Oxford University Press, New York. p. 179-227.

Ayala, R., T. Griswold y D. Yanega. 1996. Apoidea. In Biodiversidad, taxonomía y biogeografía de artrópodos de México, J. E. Llorente, A. García Aldrete y E. GonzálezSoriano (eds.), Universidad Nacional Autónoma de México, México, D.F. p. 423-464.

Ayala, R. 2004. Fauna de abejas silvestres (Hymenoptera: Apoidea), p. 193-219. In Artrópodos de Chamela, Ayala, R. y A. N. García-Aldrete 2004. Instituto de Biología, UNAM, México, D.F. 221 p.

Bravo-Hollis, H. 1978. Las cactáceas de México. Instituto de Biología. Universidad Nacional Autónoma de México, México, D.F. 743 p.

Bullock, S. H. 1986. Climate of Chamela, Jalisco, and trends in the south costal region of Mexico. Archives for Meteorology, Geophysics, and Bioclimatology 36:297-316.

Bullock, S. H. 1988. Rasgos del ambiente físico y biológico de Chamela, Jalisco, México. Folia Entomológica Mexicana 77:5-17.

Cervantes, S. L., J. M. Mass y R. Domínguez. 1988. Relación lluvia-escurrimiento en un sistema pequeño de cuencas de selva baja caducifolia. Ingeniería Hidráulica de México II época 3:30-42.

Danforth, B. 1989. Nesting behavior of four species of Perdita (Hymenoptera: Andrenidae). Journal of the Kansas Entomological Society 62:59-79.

Danforth, B. 1991. Female foraging and intranest behavior of communal bee, Perdita portalis (Hymenoptera: Andrenidae). Annals of the Entomological Society of America 84:537548.

Danforth, B. y J. Neff. 1992. Male polymorphism and polytheism in Perdita texana (Hymenoptera: Andrenidae). Annals of the Entomological Society of America 85:617- 626.

Dominey, W.J. 1984. Alternative mating tactics and evolutionarily stable strategies. American Naturalist 24:385-396.

Eickwort, G. 1977. Aspects of the nesting biology and descriptions of immature stages of Perdita octomaculata and
P. halictoides (Hymenoptera: Andrenidae). Journal of the Kansas Entomological Society 50:577-599.

García, E. 1973. Modificaciones al sistema de clasificación climático de Köppen. Instituto de Geografía, Universidad Nacional Autónoma de México, México, D.F. 246 p.

Guardado, M. E. 1996. Algunos aspectos de la historia natural de Diadasia knabiana Cockerell (Hymenoptera: Anthophoridae), en la Estación de Biología Chamela (IBUNAM), Jalisco, México. Tesis, División de Ciencias Biológicas y Ambientales, Universidad de Guadalajara, Jalisco. $66 \mathrm{p}$.

Lin, N. y C. D. Michener. 1972. Evolution of sociality in insects. Quarterly Review of Biology 47:131-159.

Lott, E. J. 1985. Listados florísticos de México. III. La Estación de Biología Chamela, Jalisco, México. Instituto de Biología, UNAM, México, D.F. 47 p.

Michener, C. D. 1953. The biology of a leafcutter bee (Megachile breves) and its associates. University of Kansas Society Bulletin 35:1659-1748.

Michener, C. D. 1974. The social behavior of the bees: a comparative study. Belknap, Cambridge, Massachusetts. $404 \mathrm{p}$.

Michener, C. 2000. The bees of the world. The Johns Hopkins University Press, Baltimore, Maryland. 913 p.

Michener, C. D. 2007. The bees of the world. Johns Hopkins University Press, Baltimore, Maryland. 972 p.

Neff, J. y B. Danforth. 1992. The nesting and foraging behavior of Perdita texana (Cresson) (Hymenoptera: Andrenidae). Jounal of the Kansas Entomological Society 64:394-405.

Rozen, J. G. 1971. Biology and immature stages of Morocan Panurginae bees. American Museum Novitates 2457:1-37.

Rozen, J. G. y S. L. Buchmann. 1990. Nesting biology and immature stages of the bees Centris caesalpiniae, $C$. pallida, and the Cleptoparasite Ericrocis lata (Hymenoptera: Apoidea: Anthophoridae). American Museum Novitates 2985:1-30.

Rozen, J. G. 1992. Biology of the bees Ancylandrena larreae (Andrenidae: Nomadinae) with a review of egg deposition in the Nomadinae (Hymenoptera. Apoidea). American Museum Novitates 3038:1-15.

Snelling, R. y B. Danforth. 1992. a review of Perdita subgenus Macrotera (Hymenoptera: Andrenidae). Contributions in Science 436:1-12.

Tauber, M. J., C. A. Tauber y S. Masaki. 1986. Seasonal adaptations of insects. Oxford University Press, New York. $411 \mathrm{p}$.

Thornhill, R. y J. Alcock. 1983. The evolution of insect mating systems. Harvard University Press. 547 p.

Timberlake, P. H. 1958. A revisional study of the bees of the genus Perdita F. Smith, with special reference to the fauna of the pacific coast. Part III. University of California Publications in Entomology 14:303-410.

Timberlake, P. H. 1960. A revisional study of the bees of the genus Perdita F. Smith, with special reference to the fauna of the pacific coast. Part IV. University of California Publications in Entomology 17:1-156. 